Revista de la red interuniversitaria de estudios sobre las literaturas rioplatenses contemporáneas en Francia

$9 \mid 2013$

Homenaje a Ana María Barrenechea

\title{
Ana María Barrenechea y su “circunstancia mexicana"
}

\section{Rose Corral}

\section{OpenEdition}

\section{Journals}

Edición electrónica

URL: http://journals.openedition.org/lirico/1081

DOI: $10.4000 /$ lirico.1081

ISSN: 2262-8339

Editor

Réseau interuniversitaire d'étude des littératures contemporaines du Río de la Plata

\section{Referencia electrónica}

Rose Corral, « Ana María Barrenechea y su "circunstancia mexicana" », Cuadernos LIRICO [En línea], 9 | 2013, Puesto en línea el 01 septiembre 2013, consultado el 01 mayo 2019. URL : http:// journals.openedition.org/lirico/1081; DOI : 10.4000/lirico.1081

Este documento fue generado automáticamente el 1 mayo 2019.

\section{(c) $(1) \odot$}

Cuadernos LIRICO está distribuido bajo una Licencia Creative Commons Atribución-NoComercialSinDerivar 4.0 Internacional. 


\title{
Ana María Barrenechea y su "circunstancia mexicana"
}

\author{
Rose Corral
}

"Ya veo que México la ha atrapado..." (Cartas

1937-1954, 551)

Carta de Julio Cortázar a Ana María Barrenechea

(21 de septiembre de 1954)

1 En este homenaje a Ana María Barrenechea nuestro propósito es volver sobre la fecunda estancia de la investigadora argentina en México en 1954 y mostrar que aunque breve, este "verano inolvidable" al cual se refirió en la "Advertencia" al libro sobre Borges que publicara en El Colegio de México en 1957 (Barrenechea, La expresión de la irrealidad 7), será una etapa decisiva de su periplo vital y académico. El título de nuestro trabajo retoma el de un artículo que escribió Barrenechea para conmemorar en 1973 los cincuenta años de la creación del Instituto de Filología y Literaturas Hispánicas "Dr. Amado Alonso". ${ }^{1}$ En este artículo se centra en tres cuentos del escritor mexicano Juan José Arreola, "El cuervero", "Pueblerina" y "Corrido", publicados en Varia invención (1949) y Confabulario (1952), un escritor que Barrenechea había conocido y tratado en 1954 y a quien puso en contacto, al igual que lo hiciera Emma Speratti Piñero, con Julio Cortázar, que ya residía entonces en París. Inmediatamente surgieron afinidades entre ambos escritores que explicarán la presencia poco después de Cortázar en la Revista Mexicana de Literatura y la publicación en 1956 de su segundo libro de cuentos, Final de juego, en la colección "Los Presentes", que dirigía Arreola en México. Que sepamos, es el único escritor mexicano al que Barrenechea dedicó un trabajo que, además de ser un análisis literario, parece ser también un tributo al aprecio y admiración que sentía por su obra única. A finales de los años noventa escribió una semblanza de Alfonso Reyes con la que participó en la mesa inaugural del coloquio internacional Norte y sur: la narrativa rioplatense desde México, en lo que fue su última visita a El Colegio de México ("Alfonso Reyes” 27-36). Aunque la amistad entre Cortázar y Ana María Barrenechea había empezado unos años antes en Buenos Aires cuando los presentó Daniel Devoto en el café La Fragata (Link), la primera carta dirigida a Ana María Barrenechea que recoge la 
correspondencia de Cortázar en cinco volúmenes es precisamente la que le escribe el escritor a México en septiembre de 1954. De esta carta hemos extraído el fragmento que aparece en el epígrafe a nuestro trabajo porque alude, mejor que cualquier otro testimonio, a la experiencia humana y vital que significó para ella su estancia en México que le dejaría, no cabe la menor duda, un recuerdo indeleble.

2 A esta correspondencia de Cortázar, a la que volveremos, pues ilumina algunos aspectos de la estancia mexicana de Barrenechea, hay que agregar la que cruzó con Alfonso Reyes y también con el hispanista y filólogo mexicano Antonio Alatorre quien, desde 1953, se queda al frente de la Nueva Revista de Filología Hispánica (NRFH) y del Centro de Estudios Filológicos, hoy Centro de Estudios Lingüísticos y Literarios de El Colegio de México, al dejar Raimundo Lida El Colegio para incorporarse a la Universidad de Harvard.

Antes que nada, debemos preguntarnos : ¿cómo llega Ana María Barrenechea a El Colegio de México en 1954 ? Hay que hacer primero un poco de historia y empezar diciendo que existe una clara continuidad entre el Instituto de Filología de la Universidad de Buenos Aires y el Centro de Estudios Lingüísticos y Literarios, así como entre la Revista de Filología Hispánica y la Nueva Revista de Filología Hispánica. Alfonso Reyes, presidente desde 1940 de El Colegio de México, será el artífice de esta continuidad. También hay que decir que sin lo que podríamos llamar la tradición filológica hispanoamericana, que se inicia en 1923 con la creación del Instituto de Filología en la Universidad de Buenos Aires, del cual fue director entre 1927 y 1946 el investigador español Amado Alonso, formado en el Centro de Estudios Históricos de Madrid, no se explicaría esta continuidad. En su Historia de la cultura en la América Hispánica (1947), escrita poco antes de que por razones políticas se cerrara el Instituto en 1946, Pedro Henríquez Ureña destacaba la relevancia del Instituto y el papel que tenía ya para Hispanoamérica :

El Instituto de Filología de la Universidad de Buenos Aires, fundado en 1923 [...], es hoy el centro principal de investigación filológica hispanística en el mundo, y ha dado a conocer, junto con los trabajos del director [Amado Alonso], estudios importantes de María Rosa Lida, Raimundo Lida, Ángel Rosenblat y Eleuterio F. Tiscornia. En la Universidad de Cuyo (Argentina), en Santiago de Chile, en Montevideo y en Bogotá se han organizado institutos que tratan de imitar este modelo. (134)

Inmediatamente después, Henríquez Ureña se refería a la fundación de El Colegio de México, a la diáspora española que la institución había acogido después de la Guerra Civil pero, por la fecha de publicación de su libro, todavía no aludía al cierre del Instituto y al ofrecimiento de Alfonso Reyes de proseguir en México las labores del Instituto. Reyes, que también había colaborado activamente en las tareas del Centro de Estudios Históricos de Madrid, en los años en que vive en la capital española y durante los cuales conoce a Alonso, recuerda que quiso que éste se "embarcara" desde España, a principios de los años 20, "con rumbo a México, para que aquí estableciera los estudios de dialectología y fonética, encaminados a levantar algún día la carta del castellano en nuestro país" (1953 : 1). El proyecto no se logró, tal vez porque el país apenas estaba reorganizándose después de los diez caóticos años que duró la Revolución. Cuando, durante el peronismo, se cierra el Instituto en Buenos Aires, se detiene la publicación de la Revista de Filología Hispánica fundada por Alonso en 1939 y éste se traslada a la Universidad de Harvard, Alfonso Reyes le abre las puertas de El Colegio de México para proseguir con la revista. Aunque la historia que sigue es conocida, creo que no es ocioso recordarla porque sin esta historia no se explican los estrechos lazos que se tejieron entre las instituciones de ambos países. La posterior presencia de Ana María Barrenechea en el Colegio de México y sus múltiples 
colaboraciones en la NRFH tienen en buena medida su origen en esta historia. En una muy puntual síntesis, Antonio Alatorre la ha recordado así :

La NRFH se llama así por ser la sucesora de la Revista de Filología Hispánica publicada entre 1939 y 1946 por el Instituto de Filología de Buenos Aires bajo la dirección de Amado Alonso. Al quedar brutalmente suprimido el Instituto, y con él la RFH, Alfonso Reyes abrió las puertas de El Colegio de México para que aquí siguieran viviendo el uno y la otra. El actual Centro de Estudios Lingüísticos y Literarios, llamado de "Estudios Filológicos" en sus primeros tiempos, fue fundado a mediados de 1947 por Raimundo Lida, discípulo predilecto de Alonso. Es, pues, continuación del Instituto de Filología de Buenos Aires. $(1997: 1)$

5 Unos años antes, en 1938, Barrenechea, cuyos maestros en el Instituto de Filología habían sido Amado Alonso y Pedro Henríquez Ureña ${ }^{2}$, conoce en el Instituto de Filología de Buenos Aires al futuro Presidente de El Colegio de México, Alfonso Reyes, durante su segunda estancia como embajador de México en Argentina. Ya se sabe de los lazos perdurables que en unos pocos años, durante sus dos embajadas, supo tejer Reyes con el medio cultural argentino, tanto con los escritores consagrados como con los más jóvenes, Ricardo Molinari, Jorge Luis Borges, Leopoldo Marechal, Francisco Luis Bernárdez entre otros. La investigadora ha recordado que "Reyes visitaba a Amado Alonso en el Instituto de Filología” y que "daba conferencias de visión integradora de lo peninsular y lo hispanoamericano" (“Alfonso Reyes” 31-32). Además, junto con Pedro Henríquez Ureña, Amado Alonso y Américo Castro, Alfonso Reyes organizaría en Buenos Aires memorables jornadas de lectura de los clásicos españoles (Góngora, el Quijote, Calderón de la Barca, San Juan de la Cruz) para darlos a conocer a un público común, no de especialistas.

6 Años después, la propia Ana María Barrenechea fue alcanzada por la Historia de su país (como lo sería nuevamente en el futuro, en los años sesenta y los setenta) y, en 1953, perdió su trabajo en el Instituto Superior del Profesorado. Gracias a una de sus profesoras, Frida Weber de Kurlat, consiguió una beca ese mismo año para ir a estudiar un doctorado sobre la obra de Jorge Luis Borges en los Estados Unidos, en Bryn Mawr College. Entre tanto, Ana María había empezado a colaborar desde Buenos Aires en la NRFH que publica en 1953 un importante ensayo suyo, "Borges y el lenguaje", en el número doble de homenaje a Amado Alonso. Como Raimundo Lida ya había dejado El Colegio para irse como profesor a la Universidad de Harvard, será entonces con Antonio Alatorre, "Secretario" de la Nueva Revista de Filología Hispánica, con quien empieza en mayo de 1953 un diálogo epistolar, antes de conocerlo personalmente en 1954. Menos formales que las breves misivas intercambiadas con Reyes, muy pronto se instala entre ambos un diálogo amistoso en el que se entreveran las noticias de familia con las cuestiones académicas. Lida le aconseja a Ana María agregar a su texto en prensa en la NRFH una referencia a un texto de Paul Bénichou que acababa de aparecer el año anterior en la revista Critique (1952 : 675-77), lo que hará en la última revisión del artículo. Posteriormente, le escribirá a Alatorre que Lida ha leído y "aprobado" el manuscrito de su futuro libro sobre Borges. Raimundo Lida, que había sido profesor suyo en el Instituto Nacional Superior del Profesorado en 1933 y a quien desde luego había tratado también en el Instituto de Filología de Buenos Aires, seguiría siendo un interlocutor muy cercano a ella en los Estados Unidos, durante su estancia doctoral en Bryn Mawr College (Barrenechea 1980 : 517-521). Como consta en sus cartas a Alatorre, Ana María revisaba con mucho cuidado el proceso de publicación de su artículo sobre Borges y luego haría lo mismo con su libro. En una carta del 26 de julio de 1956, con membrete del "Instituto de Filología" de la Facultad de Filosofía y Letras de la Universidad de Buenos Aires, le escribe a Alatorre : “...tengo la 
mala costumbre de corregir en pruebas de imprenta. Con Borges se ha agudizado mi defecto por la prisa de enviártelo antes de venirme para Buenos Aires" y le pide que le envíe el libro "en pruebas de galera" (Alatorre y Barrenechea). De vuelta a Buenos Aires, seguirá ampliando y actualizando la bibliografía de Borges y sobre Borges que acompaña su libro: le cuenta a Alatorre que además de su propio archivo que fue elaborando a lo largo de los años, visita la casa de Borges para agregar lo que conserva el escritor.

7 Antes de su partida para los Estados Unidos en 1953, también le escribía de tanto en tanto a Alfonso Reyes, para pedirle colaboraciones para la revista Buenos Aires Literaria, de cuyo consejo de redacción Barrenechea formaba parte. Al enterarse en 1954 de las dificultades económicas de Ana María Barrenechea en los Estados Unidos, Alfonso Reyes, siempre generoso y solidario, le ofrece un puesto de investigadora para seguir trabajando en El Colegio en su tesis doctoral durante el verano de ese año. Ya en México publica en la revista Universidad de México "Una ficción de Borges", un estudio que será retomado en el volumen que le dedica a Borges la revista francesa L'Herne en 1964, un ensayo en el que pone a dialogar varios textos del escritor en torno a algunos de los temas que lo obsesionan, como el del "infinito", tanto en el ensayo "La biblioteca total" publicado en Sur en 1939 como en el cuento posterior, "La biblioteca de Babel", que desarrolla "la metáfora de la biblioteca-universo". Muy pronto Barrenechea destaca en el "arte de escritor" de Borges, la

insuperable capacidad de dar a una construcción metafísica o a un problema intelectual la vida de una 'aventura' del pensamiento [...] con todo su dramatismo, sus sorpresas, sus anhelos, sus desfallecimientos y sus fracasos. (1954:20)

Durante su estancia en México, Barrenechea participa con entusiasmo en las reuniones periódicas del Centro, en "las que le parecía volver a vivir la vida del Instituto de Filología de Buenos Aires, con la predominante tonada mexicana, intercalada de alguna peruana, porteña, española o guatemalteca" ("Alfonso Reyes" 34), aludiendo con ello a los investigadores de distintos países que trabajaban entonces en el Centro de Estudios Filológicos. En 1957, y gracias nuevamente a la invitación de Alfonso Reyes, El Colegio publicó la primera edición de su tesis sobre Borges, La expresión de la irrealidad en la obra de Borges, un libro clásico que estudia de manera sistemática, en toda su obra, cómo el escritor "ha construido su nítido orbe de sombras a través de cinco temas centrales (el infinito, el caos, la personalidad, el tiempo y la materia) y de otros temas secundarios relacionados con ellos" (1957 : 16). En febrero de 1962 le escribía a Antonio Alatorre que se

[había] quedado con un grandísimo material sin utilizar por exigencias 'estéticas' del libro en sí. Por ejemplo, la parte de la filosofía idealista que había estudiado muy detalladamente y no expuse (como tampoco expuse otros aspectos filosóficos) para no abrumar una obra como la de Borges con pedantescas referencias. (Alatorre y Barrenechea)

9 Este estudio se reeditó en Argentina en dos oportunidades, la última en el año 2000 junto con otros catorce ensayos sobre Borges, "una tarea que abarca cerca de cincuenta años", dice Barrenechea (La expresión de la irrealidad en la obra de Jorge Luis Borges y otros ensayos 5). Ana María Barrenechea recordaría en 1999 el gesto de Alfonso Reyes con las siguientes palabras :

Dediqué el libro a mis maestros Amado Alonso y Pedro Henríquez Ureña y en una 'Advertencia' escrita ya de vuelta a Buenos Aires, agradecí a mi director Ferrater Mora y a todos los que lo habían hecho posible, entre ellos a El Colegio de México y especialmente a don Alfonso Reyes. Todos esos nombres juntos eran un símbolo de 
amistades que reunían la cultura de América: dos grandes escritores, Reyes y Borges; amigos entrañables Reyes, Henríquez Ureña y Alonso que habían sido avanzadas de nuestra civilización en lengua española de un lado y otro del Atlántico. (“Alfonso Reyes" 35)

10 En 1954, con Emma Speratti Piñero se dieron asimismo a la tarea de dar a conocer en México la literatura fantástica argentina, en un ciclo de charlas dictadas en el Aula Magna de El Colegio de México bajo el patrocinio de la Dirección de Difusión Cultural de la UNAM, en las que incluyeron obras de Lugones, Horacio Quiroga, Macedonio Fernández, Borges, desde luego, y los cuentos de un joven escritor argentino, Julio Cortázar, que vivía en París, y que había publicado un libro de cuentos fantásticos, Bestiario, en 1951. Su obra muestra, escribirá Barrenechea en 1957 en la introducción a La literatura fantástica en Argentina, el libro que resultó de aquellas charlas, "la vitalidad de un género que aún sigue apasionando a escritores jóvenes que encuentran fórmulas nuevas para expresar el perpetuo misterio del universo" (Barrenechea y Speratti 1957 : XIV). También destacaba el giro que da la literatura fantástica argentina, la entrada en "un ámbito distinto" a partir de la obra de Macedonio, Borges y de "otros escritores de su generación", o sea después del modernismo :

El universo se desintegra, la llamada realidad se convierte en una fantasmagoría, en un vacío, en una sombra o en una ficción literaria, y al fin acabamos dudando de nosotros mismos al dudar de todo lo que nos rodea. Junto a este hecho fundamental aparece otro no menos importante : la introducción del plano literario dentro del ámbito que el relato presenta como real ; los cruces de lector, autor, obra, vida y crítica literaria ; el borrar los límites entre la vida y la ficción artística. (XIV)

11 Es una lástima que el libro que recoge los estudios de ambas investigadoras nunca haya sido reeditado. Visto a la distancia de los años transcurridos y dada la importancia que el género cobraría en Argentina y otros países del continente, este libro pionero constituye sin duda un hito esencial en los estudios del género y en la trayectoria de la propia Barrenechea, ya que seguirá trabajando el campo con estudios teóricos, como el conocido texto de 1972 en el que refuta algunos de los planteamientos de Tzvetan Todorov, ejemplificando con ficciones de varios escritores hispanoamericanos, Borges, Macedonio, Arreola, Garro, Felisberto Hernández, Cortázar, Fuentes, Bioy Casares, Anderson Imbert, Carpentier, Eliseo Diego ("Ensayo de una tipología de la literatura fantástica"). Además del estudio introductorio, Ana María se encargó del texto dedicado a Borges y de otro sobre "La creación de la nada en el humorismo de Macedonio Fernández" que había publicado con algunas variantes unos años antes en la revista Buenos Aires Literaria. La importancia del libro publicado en México será señalada por Cortázar en una carta a su amigo Eduardo Hugo Castagnino, en mayo de 1957 : “En sendos capítulos se ocupan de Lugones, Quiroga, Macedonio, Borges y el que te escribe. El honor no es pequeño y me ha dejado turulato" (Cartas 1955-1964, 130). ${ }^{3}$

12 Pero, como recuerda Ana María Barrenechea en la semblanza que hizo de Alfonso Reyes en 1999, están presentes otras dimensiones, humanas y culturales, en la experiencia mexicana, ya que "no todo era investigación y trabajo" : recuerda las veladas musicales en casa de los Alatorre, las excursiones por el país, la "riqueza inigualada de zonas y épocas anteriores y posteriores a la Conquista", su interés por atesorar "figuras de barro o piedra" ("Alfonso Reyes" 34-5). A su regreso a los Estados Unidos le pide a Margit Frenk que le envíe "corridos u otras canciones populares (música y letra) para que las toque una graduada en Bryn Mawr College" (Alatorre y Barrenechea). A finales de 1955, desde Bryn Mawr College, poco antes de volver a la Argentina, le escribe a Alfonso Reyes : 
Norteamérica tendrá grandes bibliotecas, muchos dólares, pero una prefiere nuestros humildes pueblos hispánicos donde podría contestarse con el verso de Martí : 'pero yo tengo un amigo'. ¿Sabe usted lo difícil que es tenerlo en los Estados Unidos? Tan natural y maravillosamente que brotó la amistad en México, en poquísimos meses de vacaciones que allá pasé. (Zaïtzeff $2008: 61-62$ )

En las cartas brota asimismo su compromiso americanista, el deseo de volver a enseñar e investigar en su país, siempre que las circunstancias se lo permitieran. En una carta a Antonio Alatorre, de 1956, poco después de su regreso a la Argentina, se refiere a las condiciones inmejorables de vida y trabajo que existen en América del Norte, destaca "sus ventajas y sobre todo la sensación de seguridad que da" y las coteja con las que le esperan en su propio país: "Vivir en los países hispanoamericanos es como jugar una perpetua lotería. Pero yo debo de tener el alma de jugadora porque me gusta" (Alatorre y Barrenechea). Ello tal vez explica que nunca se estableciera definitivamente en alguna universidad norteamericana, como hubiera podido hacerlo ya que enseñó en Harvard, Ohio State y Columbia. Poco tiempo después de su regreso a Buenos Aires en 1956, concursa y gana una plaza de profesora de lengua castellana, de sintaxis y estilística, en El Colegio Nacional Central, "la vieja casa de Amadeo Jacques, foco de lucha que Perón nunca pudo dominar", le dice a Alfonso Reyes (Zaïtzeff 2008: 63). Y agregaba : “Además fue un hecho doblemente grato porque Borges formaba parte del jurado". Un par de años después, en 1958, se integraría como profesora en la Facultad de Filosofía y Letras de la Universidad de Buenos Aires hasta 1966 en que renuncia a su cargo por razones políticas.

Formada, como era usual entonces, tanto en la lingüística como en los estudios literarios, tuvo una formación sólida en ambas disciplinas y siguió a lo largo de toda su vida profundizando nuevos campos del saber porque no se conformó nunca con lo que sabía. Asociaba sus lecturas e interpretaciones de los autores que trabajaba con un interés teórico muy claro, bien acoplado a sus objetos de estudio. Aunque partió de la estilística, que había aprendido sobre todo con Amado Alonso, Ana María seguirá informándose sobre las nuevas corrientes teóricas y críticas, no por moda sino porque bien sabía que podían enriquecer la comprensión de los textos literarios. A Antonio Alatorre le informa que después de asistir al primer coloquio de la Asociación Internacional de Hispanistas en Oxford, en 1962, se fue a Copenhague "a trabajar con Hjelmslev y su equipo" (Alatorre y Barrenechea). Estaba atenta a lo que escribían los narradores y poetas en su país y en Hispanoamérica, los enseñaba en sus clases y, paralelamente, como escribió en 1987 en la $N R F H$, se interesaba por los "discursos metaliterarios contemporáneos" ("Introducción" 402). Sólo se animó a publicar el Cuaderno de bitácora de 'Rayuela' -un cuaderno hológrafo de tapas rojas, de 139 páginas numeradas por el escritor, que hoy está resguardado en la Sala del Tesoro de la Biblioteca Nacional Argentina- que Cortázar le regalara dos meses después de la publicación de la novela en $1963^{4}$, una vez asimiladas, a sus setenta años cumplidos, las herramientas que le proporcionó la nueva crítica genética, una disciplina que entonces estaba en pleno desarrollo en Francia y que le permitió ofrecer un estudio fascinante sobre la génesis de la gran novela de Cortázar. El Cuaderno de bitácora de 'Rayuela', firmado por Julio Cortázar y Ana María Barrenechea, se publicará finalmente en Buenos Aires, en la editorial Sudamericana, en diciembre de 1983, una vez regresada la democracia en la Argentina, el mes en que Cortázar viaja por última vez a su país, ya que moriría sorpresivamente dos meses después en París, en febrero de 1984. No es ocioso recordarlo este año en que se cumplen los 50 años de la publicación de Rayuela y los 30 del Cuaderno. También afloran en las cartas a Alatorre su tolerancia, su apertura al diálogo y a la crítica. Cuando Alatorre le anuncia en 1962 que James Irby entregó a la NRFH una 
reseña crítica de su libro sobre Borges, ella le contesta con humildad: "Una vez que se lanzó [un libro] al público todos tienen derecho a ponerle reparos, si también lo hacen honestamente" (Alatorre y Barrenechea).

Hemos dejado para lo último la sustanciosa y entrañable correspondencia de Cortázar, que abarca muchos años, y aunque sólo podemos leer las respuestas del escritor, inferimos claramente el contenido de las que le envió Ana María Barrenechea, Anita, como muy pronto la llama Cortázar al igual que los amigos, colegas y discípulos suyos. La correspondencia empieza con la carta enviada por Cortázar a Ana María durante su estancia en México, exactamente con la iluminadora oración que elegimos como epígrafe de nuestro artículo y que provoca unas líneas después la siguiente confesión de Cortázar en torno a México, que bien vale la pena citar :

Hace 12 años tuve la primera gran visión de México, a través de una serie de libros, poesía y cine. Razones tristemente personales me obligaron a quedarme en la Argentina, y luego pudo más mi cariño por Europa. Pero creo que un día iré allá, y me quedaré un largo tiempo ; por el momento tengo la sensación de estar mirando a través de los ojos de Emma y los suyos, y eso ya es mucho". (Cartas 1937-1954, 550)

Cortázar, qué duda cabe, supo ver mejor que nadie de qué madera estaba hecha la talentosa lectora y crítica y amiga que fue para él Ana María Barrenechea. Vale la pena citar una carta posterior de Cortázar, fechada en París el 21 de octubre de 1963, antes de que escribiera para Sur la entusiasta reseña titulada, "Rayuela, una búsqueda a partir de cero", y en respuesta a una carta anterior de Ana María en que suponemos le comenta su reciente lectura de la novela. Conmovido por su carta y porque se da cuenta de que la crítica ha captado el giro decisivo que significa Rayuela, "el golpe de timón [...] que lo está llevando a cosas mucho más interesantes que los cuentos fantásticos" (Cuaderno 127), Cortázar le contesta :

Has leído el libro un poco como yo lo he escrito, es decir al final de una larga ruta, de una inmensa biblioteca leída y vivida y decantada, vos tan serena y segura en tus juicios, vos me escribís una carta que es como una respiración profunda, que está llena de rumores y cosas apenas dichas [...] Se siente y se sabe que has ido al fondo de las cosas, y las has pesado y analizado [...] pero por un milagro que nunca te agradeceré bastante toda esa labor de sondeo y todo ese peritaje sutil que hacen de vos lo que sos como crítica y como persona, no ha conseguido petrificar lo otro, lo que llamo balbuceo a falta de mejor nombre, y entonces tu carta es como una paloma o una bola de vidrio, algo donde continuamente pasan reflejos y murmullos, y la vida [...] Logras ese raro equilibrio que sólo los más grandes logran y que en última instancia permite a la inteligencia romper sus demasiados ceñidos límites y comulgar con ese otro reino misterioso donde las cosas se mueven en la realidad profunda y son, quizá, lo único necesario. (Cartas 1955-1964, 434)

Aunque hemos preferido situar estas páginas en una órbita menos personal para recordar su paso por El Colegio de México y lo fecunda que fue su breve estancia en el país en 1954 y las múltiples repercusiones que tuvo, no quiero dejar de decir que la traté personalmente durante sus últimas visitas a nuestro Centro, primero, en 1987 cuando impartió una conferencia sobre Borges para conmemorar los cuarenta años de la fundación del Centro de Estudios Lingüísticos y Literarios y, posteriormente, cuando aceptó participar en 1999 en el coloquio internacional Norte y sur : la narrativa rioplatense desde México. También pude visitarla en 1992 en Buenos Aires, en el Instituto de Filología, en el viejo edificio de la Calle 25 de Mayo que guarda en su arquitectura mucho de su pasado majestuoso, en el microcentro de la ciudad: "Entre Cangallo y Sarmiento", me explicó por teléfono la primera vez que me reuní con ella en el Instituto, resistiéndose tal 
vez a nombrar la calle "Cangallo" por su nombre actual, "Juan Domingo Perón". Un detalle, se dirá, pero un detalle que supe muy pronto significativo de su propia biografía. Como muchos otros argentinos, Ana María Barrenechea vivió y padeció los vaivenes de la política nacional argentina a lo largo de buena parte de la compleja y muy dolorosa segunda mitad del siglo pasado. Anita se interesó generosamente -una de sus cualidades, creo, más notoria- por el trabajo que llevaba a cabo sobre literatura argentina, concretamente sobre la obra de Roberto Arlt : leyó y comentó algunos de mis borradores y me puso en contacto con estudiosos argentinos del campo, Ana María Zubieta, que acababa de publicar un libro sobre Arlt, y el escritor Ricardo Piglia. Sencillez y cordialidad en el trato, amplitud de miras, voluntad de diálogo y generosidad con sus saberes, a los que agregaría su buen humor y simpatía natural, así se impone Ana María Barrenechea en mi recuerdo personal. Conociendo su trayectoria vital, diría que también fue una persona digna, consecuente con sus ideas.

\section{BIBLIOGRAFÍA}

Alatorre, Antonio. "Presentación". En : Índices de los Tomos I-XLIV de la 'Nueva Revista de Filología Hispánica’. México : El Colegio de México, 1997, pp. 1-3.

Alatorre, Antonio y Ana María Barrenechea. "Correspondencia inédita”. Consultada en el archivo de la NRFH del Centro de Estudios Lingüísticos y Literarios de El Colegio de México.

Barrenechea, Ana María. "Macedonio Fernández y su humorismo de la nada". Buenos Aires Literaria (Buenos Aires), 9 de junio de 1953 (25-38).

Barrenechea, Ana María. “Borges y el lenguaje”. NRFH, VII, 3-4, julio-diciembre de 1953 (551-569). Barrenechea, Ana María. “Una ficción de Borges”. Universidad de México, VIII, 12, agosto de 1954 (15-20).

Barrenechea, Ana María. La expresión de la irrealidad en la obra de Jorge Luis Borges. México : El Colegio de México, 1957.

Barrenechea, Ana María . “Rayuela, una búsqueda a partir de cero”. Sur, núm. 288, 1964 (69-73).

Barrenechea, Ana María. "Ensayo de una tipología de la literatura fantástica”. Revista Iberoamericana (Pittsburgh), XXXVIII, núm. 80, 1972 (391-403).

Barrenechea, Ana María. Textos hispanoamericanos. De Sarmiento a Sarduy. Caracas : Monte Ávila Editores, 1978.

Barrenechea, Ana María. “En memoria de Raimundo Lida”. Revista Iberoamericana (Pittsburgh), XLVI, núms. 112-113, 1980 (517-521).

Barrenechea, Ana María. “Introducción”. NRFH, XXXV, 2, 1987 (401-409). [Número monográfico sobre literatura hispanoamericana]

Barrenechea, Ana María. La expresión de la irrealidad en la obra de Jorge Luis Borges y otros ensayos. Buenos Aires : Ediciones del Cifrado, 2000. 
Barrenechea, Ana María. “Alfonso Reyes : embajador de la cultura de México“. En : Rose Corral, Hugo J. Verani y Ana María Zubieta (eds.). Norte y sur : la narrativa rioplatense desde México. México : El Colegio de México, 2000, pp. 27-36.

Barrenechea, Ana María y Emma Susana Speratti Piñero. La literatura fantástica en Argentina. México : Imprenta Universitaria, 1957.

Bénichou, Paul. “Le monde de José (sic) Luis Borges”. Critique (París), 8, núms. 63-64, 1952 (675687).

Cortázar, Julio. Cartas 1937-1954. Ed. a cargo de Aurora Bernárdez y Carles Álvarez Garriga, t. 1. Buenos Aires : Alfaguara, 2012.

Cortázar, Julio. Cartas 1955-1964. Ed. a cargo de Aurora Bernárdez y Carles Álvarez Garriga, t. 2. Buenos Aires : Alfaguara, 2012.

Cortázar, Julio y Ana María Barrenechea. Cuaderno de bitácora de ‘Rayuela’. Buenos Aires : Sudamericana, 1983.

Henríquez Ureña, Pedro. Historia de la cultura en la América Hispánica. México : Fondo de Cultura Económica, 1947.

Homenaje al Instituto de Filología y Literaturas hispánicas "Dr. Amado Alonso" en su cincuentenario 1923-1973. Buenos Aires : Artes Gráficas Bartolomé U. Chiesino, 1975.

Lerner, Isaías. “Ana María Barrenechea, hispanista global”. El País (Madrid), 4 de abril de 2012.

Link, Daniel. “Una chica del 2000. Entrevista a Ana María Barrenechea”. Linkillo (cosas mías). 4 de abril de 2012. Linkillo.blogspot.com. Consultado el 8 de julio de 2013.

Reyes, Alfonso Reyes. “Amado Alonso”. NRFH, VII, núms. 1-2, 1953 (1-2).

Schwartz Lerner, Lía e Isaías Lerner (eds.). Homenaje a Ana María Barrenechea. Madrid : Castalia, 1984.

Sommers, Joseph. After the Storm. Landmarks of the Modern Mexican Novel. Albuquerque: University of New Mexico Press, 1968.

Zaïtzeff, Serge I. (comp.). 20 epistolarios rioplatenses de Alfonso Reyes. México : El Colegio Nacional, 2008.

\section{NOTAS}

1. Ana María Barrenechea, "Elaboración de la 'circunstancia mexicana' en tres cuentos de Arreola", en: Homenaje al Instituto de Filología y Literaturas Hispánicas "Dr. Amado Alonso" en su cincuentenario 1923-1973 (20-28). Este artículo se incorpora al conjunto de trabajos de Barrenechea que apareció con el título : Textos hispanoamericanos. De Sarmiento a Sarduy (235-246). La expresión "circunstancia mexicana" la toma del libro que sobre la narrativa moderna de México había publicado poco antes Joseph Sommers (After the Storm. Landmarks of the Modern Mexican Novel) para referirse a un grupo de narradores, entre los cuales están Arreola, Elena Garro, José Revueltas y otros, quienes se ocupan en sus obras "del hombre en su circunstancia mexicana".

2. En el obituario que Isaías Lerner le dedicó en la sección de cultura del periódico El País en 2012, al conocerse la noticia de su desaparición, ocurrida en realidad el 4 de octubre de 2010, señalaba que: "Con su muerte, desaparece la última representante de la extraordinaria generación de jóvenes estudiosos formados por Amado Alonso...". Véase Lerner, “Ana María Barrenechea, hispanista global". 
3. En una entrevista del año 2000, Ana María Barrenechea dijo estar preparando un libro que reuniera todos sus trabajos sobre el género fantástico, porque todos "siempre se acuerdan de aquel artículo en que critiqué a Todorov" (Link).

4. Cortázar le envía el cuaderno con un breve y sencillo mensaje, fechado en París, agosto de 1963: “Te prometí este cuaderno de trabajo y aquí te lo lleva Eduardo [Eduardo Jonquières, pintor y poeta, amigo común]. No vale nada, pero me gusta pensar que lo vas a guardar vos, que tan cerca has estado siempre de mis libros y de mi afecto". (Cartas 1955-1964, 424)

\section{RESÚMENES}

En este artículo nos proponemos documentar la decisiva estancia de Ana María Barrenechea en El Colegio de México en 1954 y las afortunadas consecuencias que tuvo, tanto en el terreno personal, al tejer amistades con el grupo de filólogos mexicanos y latinoamericanos que había formado Raimundo Lida -discípulo de Amado Alonso en Buenos Aires- entre 1947 y 1953 en el Centro de Estudios Filológicos, como en el intelectual y académico, ya que publicó en México un libro hoy clásico, La expresión de la irrealidad en la obra de Jorge Luis Borges, y varios ensayos sobre literatura argentina. Junto con su colega argentina Emma Speratti Piñero, quien pasó en los años cincuenta una larga temporada en El Colegio, dieron a conocer la literatura fantástica argentina en un ciclo de conferencias, un interés por el género que nunca por cierto la abandonaría. La correspondencia de Julio Cortázar así como la que intercambió Barrenechea con Alfonso Reyes y la que se conserva en los archivos de la Nueva Revista de Filología Hispánica, han permitido reconstruir algunos de los lazos de Barrenechea con México.

Cet article documente le séjour décisif que réalisa Ana María Barrenechea au Colegio de México en 1954 et ses heureuses conséquences, aussi bien sur le plan personnel, puisqu'il lui permit de nouer des amitiés durables avec le groupe des philologues mexicains et latino-américains formé par Raimundo Lida -disciple d'Amado Alonso à Buenos Aires-, entre 1947 et 1953, que sur le plan intellectuel et académique, puisqu'elle publia au Mexique un livre aujourd'hui classique, La expresión de la irrealidad en la obra de Jorge Luis Borges, et plusieurs essais sur la littérature argentine. Avec sa collègue argentine, Emma Speratti Piñero, qui s'intégra dans les années 50 au groupe de recherche du Colegio, elles donnèrent aussi plusieurs conférences sur la littérature fantastique en Argentine. Barrenechea approfondira par la suite cet intérêt pour le genre fantastique. Sa correspondance avec Julio Cortázar, Alfonso Reyes et, de même, celle qui se trouve dans les archives de la Nueva Revista de Filología Hispánica, ont permis de mieux reconstruire certains liens qui unirent Barrenechea avec le Mexique.

This paper seeks to document the importance of Ana María Barrenechea's stay in the Colegio de México during 1954 and to analyse its consequences both on the personal level (in the Centre of Philological Studies between 1947 and 1953 she formed friendships with the group of Mexican and Latin American philologists who were formed by Raymundo Lida, a disciple of Amado Alonso) and on the academic and intellectual level (in Mexico she published the now classic study, La expresión de la irrealidad en la obra de Jorge Luis Borges, and several essays on Argentine literature). With her Argentinian colleague Emma Speratti Piñero, who spent a long period in the Colegio de México in the 1950s, she gave a series of talks on the fantastic literature of Argentina and she would never abandon this interest in the genre. Some of the many facets of 
Barrenechea's relationship with Mexico can be reconstructed from the correspondence she exchanged with Julio Cortázar and with Alfonso Reyes, as well as from the letters that remain in the archives of the Nueva Revista de Filología Hispánica.

ÍNDICE

Mots-clés: Ana María Barrenechea, tradition philologique, Argentine et Mexique, littérature fantastique argentine

Keywords: philological tradition, Argentina and Mexico, fantastic literature in Argentina Palabras claves: tradición filológica, Argentina y México, literatura fantástica argentina

\section{AUTOR}

\section{ROSE CORRAL}

Centro de Estudios Lingüísticos y Literarios. El Colegio de México rcorral@colmex.mx 